\title{
Analisis Kualitatif Sakarin dan Silamat pada Es Doger di Kota Batam
}

Hesti Marliza, Delladari Mayefis*, Raihani Islamiati

Program Studi Sarjana Farmasi, STIKes Mitra Bunda Persada, Batam

*Corresponding author: dellamayefis@gmail.com

Submitted: 28 Desember 2019

Accepted: 15 Januari 2020

Published: 29 Februari 2020

\begin{abstract}
Background: Synthetic sweetener is a substance that can cause sweetness and calories resulting lower than sugar. The artificial sweetener that is often used by traders is saccharine and cyclamate. The ingestion of saccharine and cyclamate in high dosages can cause cancer, and other diseases such as lung tumors, liver, lymph migraine, and headache. Objective: The purpose of this research was to know the presence or absence of saccharine and cyclamate in Doger Ice sold in some areas of Batam. Methods: This research used the experimental method with the sampling technique with the accidental sampling method which is an accidental sampling or available as many as 12 samples from 12 Doger Ice merchants. Results: The sample identification was performed qualitatively with precipitation tests and color reaction tests. The results showed that as many as 12 samples from 12 merchants in some areas of Batam did not contain saccharine and cyclamate. Conclusion: Doger ice sold in Batam City does not contain artificial sweeteners.
\end{abstract}

Keywords: synthetic sweeteners, saccharine, cyclamate

\begin{abstract}
Abstrak
Pendahuluan: Pemanis sintetis merupakan suatu zat/bahan yang digunakan untuk menimbulkan rasa manis dengan jumlah kalori yang lebih rendah daripada gula pasir. Salah satu pemanis buatan yang sering digunakan adalah sakarin dan siklamat. Konsumsi sakarin dan siklamat dalam dosis tinggi dapat menyebabkan kanker, dan penyakit lainnya seperti tumor paru, hati, limfa, migraine dan sakit kepala. Tujuan: Penelitian ini bertujuan untuk mengetahui kandungan sakarin dan siklamat pada es doger yang dijual di beberapa lokasi di Kota Batam. Metode: Penelitian ini menggunakan metode eksperimental dengan metode pengambilan sampel yang kebetulan ada atau tersedia saat itu sebanyak 12 sampel dari 12 pedagang es doger. Identifikasi sampel dilakukan secara kualitatif dengan uji pengendapan dan uji reaksi warna. Hasil: Hasil uji menunjukkan bahwa sebanyak 12 sampel dari 12 pedagang di beberapa lokasi di Kota Batam tidak mengandung sakarin dan siklamat. Kesimpulan: Es doger yang dijual di Kota Batam tidak mengandung pemanis buatan.
\end{abstract}

Kata kunci: pemanis buatan, sakarin, siklamat

\section{PENDAHULUAN}

Bahan tambahan makanan merupakan bahan tambahan dan bukan bahan utama yang digunakan pada makanan, yang digunakan untuk memperoleh produk makanan atau minuman yang enak, menarik, dan tahan lama (Rasyid dkk., 2011).

Salah satu bahan tambahan makanan yang digunakan adalah pemanis. Di pasaran tersedia 2 jenis pemanis yaitu pemanis alami dan pemanis buatan.
Pemanis alami/sukrosa berasal dari tanaman tebu (Saccharum officinarum L.), dan bit (Beta vulgaris L.) (Rasyid dkk., 2011). Sedangkan pemanis buatan merupakan zat/bahan dengan rasa manis dan jumlah kalori yang lebih rendah daripada gula (Nurlailah dkk., 2017).

Penggunaan pemanis buatan sudah diizinkan penggunaannya, dan tercantum di dalam Peraturan $\begin{array}{llll}\text { Menteri } & \text { Kesehatan } & \text { RI } & \text { Nomor }\end{array}$ 
208/Menkes/Per/IV/1985 adalah siklamat, sakarin dan aspartam. Sakarin dan siklamat digunakan bagi seseorang yang melakukan diet gula, karena menghasilkan kalori yang rendah (Arini, 2018).

Sakarin memiliki tingkat kemanisan 300 kali dari gula biasa (sukrosa) dan menimbulkan rasa ikutan yang pahit sedangkan siklamat tidak menimbulkan rasa ikutan yang pahit. Siklamat memiliki tingkat kemanisan 30 kali dari pada sukrosa (Rasyid dkk., 2011).

Batas maksimum penggunaan sakarin yang di atur oleh ADI (Acceptable Daily Intake) adalah 0 - $5 \mathrm{mg} / \mathrm{BB} / \mathrm{hari}$ dan kadar maksimum penggunaan sakarin dalam minuman $300 \mathrm{mg} / \mathrm{L}$ sedangkan batas maksimum penggunaan siklamat adalah 0 - $11 \mathrm{mg} / \mathrm{BB} / \mathrm{hari}$ dan kadar maksimum penggunaan siklamat dalam minuman $3 \mathrm{~g} / \mathrm{L}$ (Lestari, 2011).

Penggunaan pemanis sintetis dalam jumlah yang berlebihan sangat tidak dianjurkan karena dapat menimbulkan efek merugikan bagi kesehatan, seperti penyakit syaraf, insomnia, hipertensi dan kanker otak (Devitria \& Sepriyani, 2018).

Penambahan sakarin dan siklamat biasanya digunakan oleh pedagang minuman, salah satunya es doger. Minuman ini cukup digemari oleh masyarakat terutama saat cuaca panas, terlebih lagi iklim di Kota Batam cenderung panas, karena secara geografis merupakan daerah kepulauan. Terlebih penelitian analisis kualitatif sakarin dan siklamat belum pernah dilakukan di Kota Batam.

\section{BAHAN DAN METODE}

\section{Bahan}

Sampel es doger, $\mathrm{BaCl}_{2} 10 \%$, eter, $\mathrm{HCl} 10 \%, \mathrm{HCl}$ $25 \%, \mathrm{H}_{2} \mathrm{SO}_{4} \mathrm{p}, \mathrm{NaNO}_{4} 10 \%, \mathrm{NaOH} 10 \%$, karbon aktif, resorsinol, natrium siklamat, sakarin.

Alat

Batang pengaduk, beaker glass, corong biasa, corong pisah, hotplate, kaca arloji, karet penghisap, kertas saring, labu ukur, pipet tetes, pipet volume, penangas, spatel, dan timbangan.

Metode

Metode eksperimental di Laboratorium Kimia Farmasi dengan analisa kualitatif uji pengendapan dan uji reaksi warna.

\section{Prosedur kerja}

\section{Pengambilan sampel}

Pengambilan sampel es doger dengan metode accidental sampling dengan sampel yang kebetulan ada atau tersedia saat penelitian.

\section{Analisis kualitatif siklamat dengan uji pengendapan (BSN, 1992)}

Sebanyak $100 \mathrm{~mL}$ sampel dimasukan ke dalam Erlenmeyer kemudian ditambahkan arang aktif hingga larut, disaring dengan kertas Whatmann 42. Di tambahkan $10 \mathrm{~mL}$ larutan $\mathrm{HCl} 10 \%$ dan $10 \mathrm{ml}$ larutan $\mathrm{BaCl}_{2} 10 \%$, didiamkan selama 30 menit, disaring kembali dengan kertas saring Whatmann 42 dan ditambahkan $10 \mathrm{~mL}$ larutan $\mathrm{NaNO}_{2} 10 \%$. Hasil reaksi dipanaskan di atas hotplate dan ditunggu sampai 20 30 menit setelah dipanaskan, kemudian diamati. Apabila terdapat endapan putih maka sampel positif mengandung siklamat.

\section{Analisis kualitatif sakarin uji reaksi warna (BSN, 1992)}

Sebanyak $50 \mathrm{~mL}$ sampel ditambahkan $5 \mathrm{~mL} \mathrm{HCl}$ $25 \%$ kemudian ekstraksi dengan $25 \mathrm{~mL}$ eter. Setelah larutan terpisah, eter diuapkan kemudian tambahkan 15 tetes $\mathrm{H}_{2} \mathrm{SO}_{4}$ pekat dan $40 \mathrm{mg}$ resorcinol (0,04 gram), kemudian panaskan di api kecil sampai berubah warna menjadi coklat. Setelah larutan dingin, tambahkan $5 \mathrm{~mL}$ aquadest dan $\mathrm{NaOH} 10 \%$ berlebih. Apabila terjadi perubahan warna menjadi hijau fluoresens (hijau kekuningan) maka sampel positif mengandung sakarin.

\section{HASIL DAN PEMBAHASAN}

Hasil penelitian analisis kualitatif sakarin dan siklamat pada minuman es doger yang dijual di berbagai daerah Kota Batam menggunakan uji pengendapan dan uji reaksi warna.

Tabel 1. Hasil uji kualitatif sakarin dan siklamat dengan uji pengendapan dan reaksi warna

\begin{tabular}{ccc}
\hline Sampel & Sakarin & Siklamat \\
\hline 1 & $(-)$ & $(-)$ \\
2 & $(-)$ & $(-)$ \\
3 & $(-)$ & $(-)$ \\
4 & $(-)$ & $(-)$ \\
5 & $(-)$ & $(-)$ \\
6 & $(-)$ & $(-)$ \\
7 & $(-)$ & $(-)$ \\
8 & $(-)$ & $(-)$ \\
9 & $(-)$ & $(-)$ \\
10 & $(-)$ & $(-)$ \\
11 & $(-)$ & $(-)$ \\
12 & $(-)$ & $(-)$ \\
\hline
\end{tabular}

Dari Tabel 1 dapat dilihat sebanyak 12 sampel yang telah diuji dengan uji reaksi warna dan uji pengendapan didapat hasil bahwa semua sampel tidak mengandung sakarin dan siklamat. 
Penelitian ini bertujuan untuk mengidentifikasi apakah es doger yang dijual di Kota Batam mengandung pemanis sintetis sakarin dan siklamat atau tidak, agar aman untuk dikonsumsi.

Penelitian ini dilakukan analisis secara kualitatif sakarin dan siklamat dalam minuman es doger yang terdiri dari 12 macam sampel es doger dari pedagang yang berbeda di beberapa daerah di Kota Batam.

Pada Gambar 1, uji kualitatif siklamat dilakukan dengan cara uji pengendapan. Pada preparasi sampel ditambahkan karbon aktif untuk menghilangkan warna pada sampel agar lebih mudah diamati reaksi-reaksi yang terjadi pada sampel. Pengendapan terjadi akibat penambahan $\mathrm{BaCl}_{2}$ (barium klorida) pada suasana asam pada sampel, tunggu selama 30 menit kemudian ditambah $\mathrm{NaNO}_{2}$ (natrium nitrit) sehingga membentuk endapan $\mathrm{BaSO}_{4}$ (barium sulfat) lalu dipanaskan di atas hotplate atau penangas air, dan ditunggu selama 30 menit kemudian hasil yang didapat setelah dilakukan pemanas adalah tidak terdapat endapan putih.

Hasil reaksi kimia yang terjadi dalam pembentukan endapan $\mathrm{BaSO}_{4}$ (barium sulfat) adalah sebagai berikut.
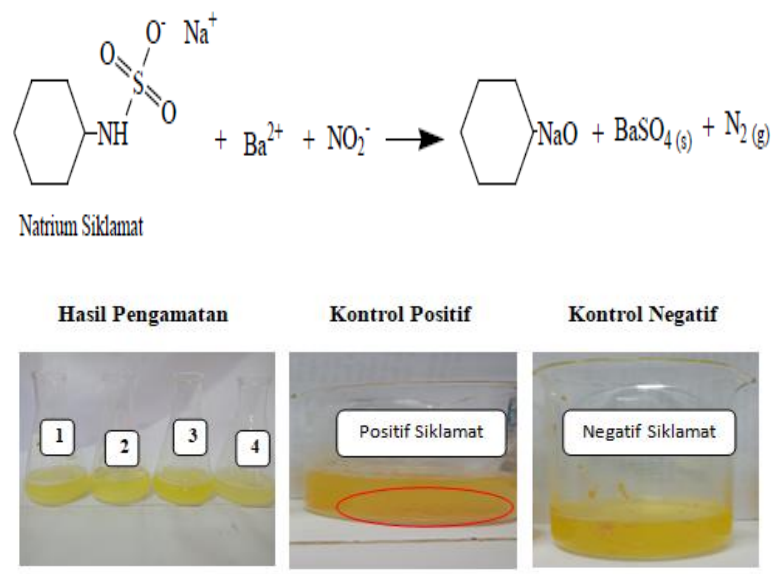

Kontrol Negatif
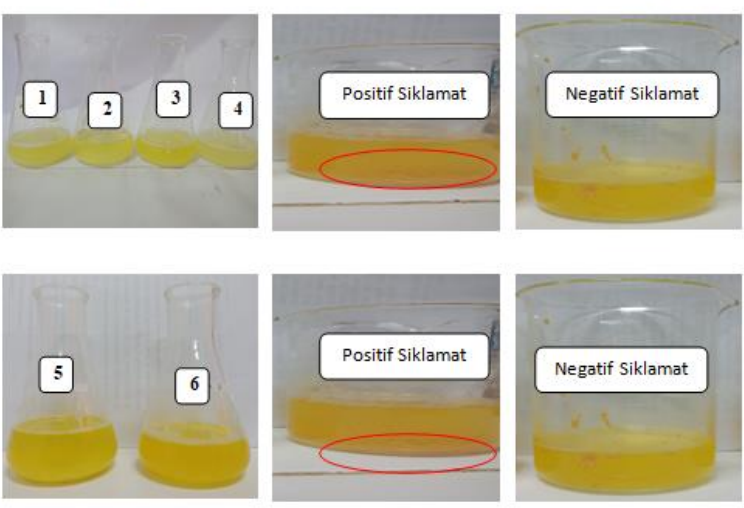

Gambar 1. Uji kualitatif siklamat

Pada Gambar 2, uji kualitatif sakarin dilakukan dengan uji reaksi warna. Uji reaksi warna dilakukan dengan menambahkan $\mathrm{HCl} 25 \%$ dengan tujuan untuk mengubah garam sakarin dalam minuman es doger menjadi asam sakarin yang tidak larut dalam air, setelah itu ekstraksi dengan eter agar asam sakarin dapat ditarik oleh eter. Kemudian hasil ekstrak tersebut dibiarkan di udara terbuka agar diperoleh sakarin, lalu tambahkan $\mathrm{H}_{2} \mathrm{SO}_{4}$ dan terbentuk $o$ benzoatsulfonamida dan bereaksi dengan resorcinol sehingga menghasilkan senyawa berwarna hijau fluoresens (hijau kekuningan). Sampel dikatakan positif apabila setelah diuji sampel mengalami perubahan warna menjadi hijau fluoresens (hijau kekuningan).
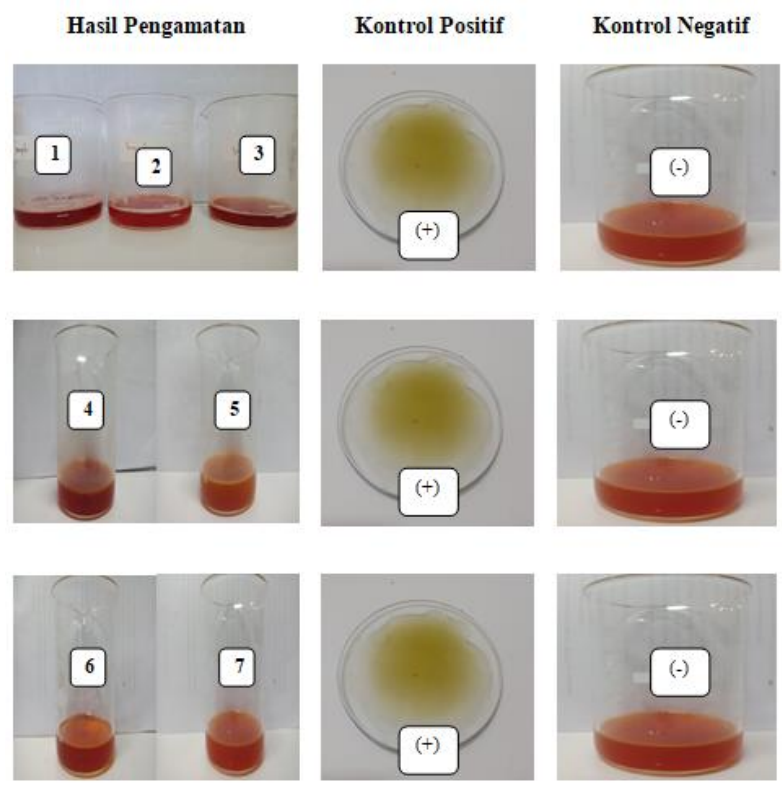

Gambar 2. Uji kualitatif sakarin

Berdasarkan penelitian yang telah dilakukan seluruh sampel tidak teridentifikasi mengandung sakarin karena setelah dilakukan pengujian tidak terjadi perubahan warna hijau fluoresens (hijau kekuningan).

\section{KESIMPULAN}

Sebanyak 12 sampel es doger di Kota Batam tidak mengandung pemanis buatan sakarin maupun siklamat, dan aman untuk dikonsumsi.

\section{UCAPAN TERIMAKASIH}

Terima kasih tak terhingga kami ucapkan kepada Prodi Sarjana Farmasi STIKes Mitra Bunda Persada Batam dalam mendukung kegiatan penelitian ini.

\section{DAFTAR PUSTAKA}

Arini, D. (2018). Identifikasi Sakarin Pada Minuman Jajanan di Kawasan Pendidikan SD di Wilayah Kecamatan Mojoroto Kota Kediri. SimkiTechsain; 2; 1-8.

Badan Standarisasi Nasional (BSN). (1992). Standar Nasional Indonesia (SNI). SNI-01-2893-1992. Cara Uji Pemanis Buatan. Jakarta: Dewan 
Standarisasi Indonesia.

Devitria, R. \& Sepriyani, H. (2018). Identifikasi Natrium Siklamat pada Minuman Sirup yang dijual di Lima SD Kecamatan Sukajadi Pekanbaru. Jurnal Analis Kesehatan Klinikal Sain; 6; 1-7.

Lestari, D. (2011). Analisis Adanya Kandungan Pemanis Buatan (Sakarin dan Siklamat) pada Jamu Gendong di Pasar Gubug Grobogan. Skripsi; Fakultas Tarbiyah Institut Agama Islam
Negeri Walisongo, Semarang.

Nurlailah, A. N. A. \& Oktiyani, N. (2017). Analisis Kadar Siklamat pada Es Krim di Kota Banjarbaru. Medical Laboratory Technology Journal; 3; 77-81.

Rasyid, R., Yohana, M. \& Mahyuddin, M. (2016). Analisis Pemanis Sintesis Natrium Sakarin dan Natrium Siklamat dalam Teh Kemasan. Jurnal Farmasi Higea; 3; 52-57. 